Price, S., Davies, P., Farr W., Jewitt, C., Roussos, G. \& Sin, G. (2012) Fostering geospatial thinking in science education through a customisable smartphone application British Journal of Educational Technology doi: 10.1111/bjet.12000

Pre-print version. Publisher's version available at http://onlinelibrary.wiley.com/doi/10.1111/bjet.12000/abstract

\title{
Fostering geospatial thinking in science education through a customisable smartphone application
}

\section{Sara Price, Paul Davies, William Farr, Carey Jewitt, George Roussos, George Sin}

Sara Price is a Senior Lecturer in Technology-Enhanced Learning at the Institute of Education (IoE). Research interests: emerging digital technologies (mobile, tangible, sensor) for supporting learning and new ways of thinking. Paul Davies is a Lecturer in Science Education (PGCE Secondary Science and MA Science Education) (IoE). Research interests: student teachers' knowledge of ecology and evolutionary biology. William Farr is a Researcher (IoE). Research interests: the use of multi-modal devices for hard to reach user groups; Carey Jewitt is Professor in Education and Technology (IoE). Research interests: representation and technology mediated learning, focusing on visual and multimodal research methods; George Roussos is a Reader in Computer Science at Birkbeck College. Research interests: distributed and pervasive computer systems and mobile commerce; George Sin is a software engineer, experienced in Android development for supporting participatory data collection. Address for correspondence: S. Price, London Knowledge Lab, 23-29 Emerald Street, London WC1N 3QS. E-mail s.price@ioe.ac.uk

\begin{abstract}
Enhanced capabilities of modern smartphones offer the potential to design tools that support new forms of teaching and learning. Increased access to mobile-networked environments and geospatial systems provide opportunities for developing new educational experiences that support a geospatial approach to science, fostering new ways of thinking about science. Yet, designing effective innovative educational mobile applications remains a challenge. Applications need to be accessible to teachers that are not tech-savvy as well as those that are, foster active learning pedagogies, enable flexible and creative use, as well as fit within the curriculum. This paper describes a smartphone application developed together with pre-service science teachers, designed to be customisable by teachers while supporting a geospatial approach to science education. The design process and trial illustrate application use, how it supports a geospatial approach to science education, and raises issues around mobile technologies, teacher pedagogies and adoption.
\end{abstract}

\section{Introduction}

The features and ubiquity of mobile technologies makes them potentially important tools in the current and future landscape of education. Whilst mobile learning promises to transform formal education (Sharples et al, 2007), school institutions acting on professional responsibilities have been reluctant to adopt mobile technology (e.g. Demirci, 2009), partly due to issues of inappropriate internet access, but also concerns about how mobile technology may change the classroom, making it more constructivist and student led (Winters and Price, 2005). This creates a potential mismatch between knowledge acquired through authority and curriculum, reflecting what teachers feel comfortable doing in practice (Sharples et al, 2007; Hagevik, 2011), and knowledge through negotiation and mutual agreement, as mobile technology works best in a dynamic and ever-changing context (Dourish, 2004). The 'fixed' character of most digital applications however offers limited utility across age, topic, and ability, as teachers lack technical skills to use such technologies flexibly in their teaching. Tools that need no specialized knowledge, and enable teachers to design and customise learning activities with relative ease are therefore potentially valuable.

Integration of global positioning systems (GPS) on smartphones, increased wireless networking, easy access to geographical information systems (GIS) such as Google Earth, integration of data collection tools, and web 2.0 technologies, offer new sets of tools to enhance teaching and learning (e.g. Anand et al., 2010) and support new ways of thinking (e.g. Vygotsky, 1986; Kirsch, 2010). These tools are fundamental in advancing spatial thinking skills, which are considered important in developing scientific understanding (Janelle and Goodchild, 2009) e.g., considering 
habitat changes through time, making sense of shapes of molecules and relating this to chemical reactions, and provide opportunities to leverage change in pedagogical approaches to teaching science.

However, integration and adoption of smartphones and GIS technologies in education remain limited (Demerci, 2009). While mobile technologies support scientific inquiry (e.g. Rogers and Price, 2008; Kanjo et al., 2007), designing effective adaptable educational mobile applications remains a challenge. This project aimed to address this by developing a customisable smartphone application, designed to support a geospatial approach to science teaching, and to foster adoption through a participatory design process involving teacher trainees. In so doing it aimed to increase pre-service teachers' (PST) capacity to orchestrate and tailor fieldwork-based learning experiences, and provide a technological and pedagogical response to the lack of teacher skills and teacher orientated software for creating learning activities using GIS.

\section{GeoSciTeach design and use}

The GeoSciTeach smartphone application is designed for teachers and their students. A participatory design methodology (Spinuzzi, 2005) was undertaken to ensure end-user input into the application design, its technical requirements, and the pedagogical design of learning activities. Eight PSTs studying for a Science Post Graduate Certification in Education (PGCE) took part. The PSTs had varying amounts of smartphone experience, thus informing a design that was useful for both non-confident and confident technology users. A series of workshops involving participants, researchers (including a science PGCE tutor) and technicians over a period of five months informed iterative design of the application, including appropriate choice of components for customisability and their role in supporting teaching of scientific and geospatial concepts. The PSTs intensive nine-month course culminates in experience of teaching outside of the classroom. Here, the PSTs work at the Royal Botanical Gardens, Kew designing and teaching sessions for students from a nearby school, making it pertinent to design an application that would have the capacity to be used in this setting.

The application was based on an exemplary science learning activity for the Princess of Wales Glasshouse, which contains a wide variety of plants from different regions of the world. Based on the question 'Why and how do humans use plants?' the application was designed to promote in situ engagement with geospatial concepts and representations in science. This was achieved through several customisable components: a camera to take pictures; a video camera to record events; data logging of abiotic factors (e.g. temperature, humidity); recording of taxonomic information about plants' characteristics; a QR code reader enabling access to teacher selected web-based information, text or pictures. Information could also be shared through social networks such as twitter, and blogs such as tumblr, and question wall pages like wallwisher. All data captured by an individual student during a session are stored on the smartphone in the form of data files using the KML (Keyhole Markup Language) schema and associated multimedia for download and viewing in Google Earth in the classroom, fostering spatial displays of data patterns and inferential level analysis (table 1). KML is an XML-based markup language, designed specifically for expressing geographic annotations on web-based systems. A KML file contains a set of geographic features such as place marks, that can be efficiently processed by a geospatial software that may transform, visualize or otherwise process this information.

\section{Table 1 here}

As contextualised learning aids collection and interaction patterns with mobile technologies (Martin et al., 2010), the camera and abiotic data were designed to automatically prompt tagging of data with its place of origin, and uploading onto Google Maps. This enables information to be mapped onto broader science learning ideas, promoting a geospatial approach to thinking about science e.g. layering on GoogleMaps displays spatial patterns of plant distribution and adaptation throughout the world. Such layering also enables students' understanding to move from descriptive to analytical and inferential levels (table 1). Detailed plant information (Plant Characteristics) could be also gathered using the camera overlay of leaf shapes (Figure 1). This software was developed as part of the project using data on average leaf morphology (e.g. see Xu, Guo, Xu, Wei, Wang, 2009). These data encourage students to look carefully at leaf structure, make comparisons between species, and begin to develop an appreciation of the importance of plant features. 
A linked mobile application (GeoSciTeacher) enables teachers to design a learning activity and select the tools to guide or support the activity. The workflow designed for a specific activity and the associated questions authored through GeoSciTeacher are encoded as machine-readable instructions that are subsequently used to configure the functionality of GeoSciTeach. Modification of this type was considered important as it allows activities to be tailored to the curriculum and specific needs of students. Potentially, this makes differentiation and personalised learning easier and allows students to take ownership of their work and 'meaningmaking'. Furthermore, the information collection exists within a walled-garden of selected scientific foci, chosen by PSTs, whilst allowing students the freedom to seek out and share information on the Internet from pre-identified sources.

\section{Figure 1 here}

Seven PSTs trialed the application at the Royal Botanical Gardens, Kew (one having withdrawn from the course). PSTs worked in small groups to design a 45 minute fieldwork activity for five different groups of three or four year 7 students (11-12 years). On the teaching day, PSTs worked in pairs, some being paired with PSTs who had not been involved in designing the application.

\section{Discussion}

The findings reported here are based on data from observation, video and interviews collected at Kew, whilst also drawing on data from across the design process. Here we focus on application design and use by PSTs and their students in a teaching/learning context, and the application's role in fostering geospatial awareness and thinking.

\section{Using customisable tools}

The PST participants had mixed experience with using mobile technologies, both from their own school experiences and teaching practice. The overall design of the application, being based on common interaction with Android phones (i.e., a menu that is familiar in both design and location, figure 2), resulted in intuitive navigation and interaction. Video and interview data showed ease of use in context, PSTs (who were novices to the application) took about 15 minutes, while students took five.

In addition, there was variation in PST beliefs about the usefulness of mobile technologies for supporting learning. Through observation and discussion throughout the project, it was apparent that PSTs confidence in using technology of this type increased but, more importantly, the application afforded them opportunities to consider different pedagogical approaches. Niess (2005) reports that exposure to specific training about the use of technology in teaching and learning increases PSTs creativity in terms of pedagogical content knowledge and similar findings were seen with GeoSciTeach; the flexibility of the application through its customisable capabilities allowing PSTs to better design activities which allowed their students to engage with scientific content. PSTs selected a number of in-application features, illustrating adaptive use with various groups of students. Primary features chosen were the Camera, QR codes, Plant Characteristics, Video and the Ambient Data section, accessible on the 'Collect Data' page (figure 3).

\section{Figure 2 and Figure 3 here}

The camera was chosen by all groups to take photographs of plants. Since photograph taking is a primary use of smartphones (Judge, 2011), GeoSciTeach aimed to exploit and enhance this by tagging photographs (figure 4). When students used the camera to collect data, other students took out their own phones to take photographs. In allowing this teachers showed a willingness to embrace the technology to engage all students in the same way - the ones with the application phone were not singled out, showing a positive attitude towards student use of personal devices. This highlights a key issue with mobile technology use in schools, where commonly smartphones are banned in classrooms, creating a tension between appropriation of these new ways of learning and existing practices (Sharples et al., 2010).

\section{Figure 4 here}

While the application is designed to foster constructivist approaches to learning and facilitative approaches to teaching, some PSTs were reluctant to let the students 'take the lead' in their learning and used the application as a tool for controlling learning and behaviour. Other PSTs 
displayed more confidence in allowing students to independently explore, which is shown to help develop individualised meaning (Bonwell and Eison, 1991). For example, some students were directed to photograph specific plants, while others were prompted to look for themselves and take as many photographs as they wanted. This illustrates how GeoSciTeach could be used to, allow students to work independently but with a guiding focus.

The ambient data section was chosen since environmental data were specifically relevant to the task. When one PST suggested students use particular data collection tools (i.e., the Camera and Ambient Data), students were initially unsure what 'ambient data' are. Using the tool they could see that it referred to a set of measurements that relate to the environment (i.e. temperature, humidity).

QR codes were used by all groups, providing a high level of flexibility for PSTs in giving students access to information not readily available in situ, or structuring the activity itself through tasks and questions. Furthermore, QR codes can link to different representations (easier or more complex) related to the same concept, something that promotes inclusive teaching. QR codes were used to help students find out about the use of specific plants, e.g. lavender and aloe vera; or Lady Gaga's latex clothing to illustrate the use of 'rubber' plants like Euphorbia. This demonstrates the potential of customisability in fostering creative approaches to teaching that speak to the interests and age of the students. While QR codes proved popular with the teachers, being described as versatile, easy to use and implement, one PST noted that they have "good scope but we just didn't use it well here". Essentially the PST wanted to place QR codes next to selected plants around Kew, something not possible within Kew's policy. As an alternative some PSTs carried QR links with them on cards, offering them to students at opportune moments.

These episodes illustrate how the PSTs customised their use of the application to draw attention to concepts, which students might not otherwise have thought about in the context of their activity, and to help structure student thinking in relation to important features about plants and their habitat. The application also offered PSTs a basic pedagogical structure, providing freedom to develop a wide variety of activities if confidence during reflection allowed (Simpson, Jackson and Aycock, 2005).

\section{Integrating the geospatial into science}

External tools and representations shape activity in different ways (e.g. Kirsch, 2010). The application, prompting uploading of pictures to Google Maps, automatically draws attention to the plant's natural location, and implicitly highlights the 'what and where', which underpins geospatial thinking (Kerski, 2008). Furthermore, it enables data sharing that supports comparison of larger data sets, something central to effective learning in science. The nature of the application encourages this by enabling the user to quickly collect and access large amounts of information: this leads to an even greater need for thoughtful selectivity and analysis before the data are shared with others. As Niess (2005) points out, teachers must now not only consider subject and pedagogical content knowledge but also integrate technology pedagogical content knowledge into their teaching. The application supports this integration through its ease of use and customisable nature. By drawing on pedagogical approaches to science learning, it thus supports the scientific concepts being explored, through a "geospatial lens".

Several examples of PSTs and students integrating geospatial ideas with science through the use of the GeoSciTeach application were evident. While explaining how to use the application, one PST made clear reference to how the application can be used for both science (specifically in relation to the question they were asking) and for accessing geospatial concepts (focusing on where things are in the world). Analysis of this PST's interaction and use of the tool demonstrates that he had a good grasp of how the application works and its application in a teaching context.

The mapping activity of GeoSciTeach i.e. recording and tagging temperature and humidity data to Google Maps encouraged students to think about the plants' natural habitats. It also helped them reflect on how commercial production of these plants would take place in different parts of the world. In essence, this allowed students to be 'transported' to different environments and begin to make sense of how human interactions can be beneficial, for example in terms of food production, but also problematic, as in how fuel are used to heat glasshouses. Follow up interviews with students revealed that they would not have considered atmospheric data to be 
important for understanding the topic, suggesting that the app fostered this thinking. In other contexts teachers could customise measurement parameters, suitably tailoring data collection.

A key theme across PST and student groups was an emphasis on physical characteristics of plants: what they looked like, and their habitat. One design feature was to draw attention to these physical features (e.g. Plant Characteristics and Camera). Data from the trials suggest that the application supported these 'scientific' concepts, and fitted well with aspects PSTs wanted their students to focus on. Several examples illustrate how the teacher is instrumental in bringing information and ideas together.

One pair of PSTs used QR codes to generate graphs of the monetary value of coffee and cocoa. Here students were exposed to a wider range of scientific related representations in context, bringing together the abstract and concrete in meaningful ways and demonstrating the value of science beyond the classroom. Another PST prompted students to look at plant and leaf characteristics, to think about how plants could be used to make money. For Bromeliads this prompted suggestions of making baskets from their 'fibrousy leaves', or to get pink dye, due to the colour of the leaves and fruits. Other groups focused on the Bromeliads' propensity to hold water in a small pool, and think about their location in the glasshouse - the climatic zone, and therefore, in the world. By mapping these data the geospatial concepts are inherently integrated into the scientific ideas being explored.

One important factor is how teachers learn to effectively use the technologies or ideas they are designed to promote - be they scientific or geospatial - and to get to the 'why' questions i.e. to go beyond the descriptive and analytic to the inferential; something that innovative technology has been shown to support (Hopson, Simms and Knezek, 2002). One PST's prompting of students to elaborate on why and how Bromeliads have water can be contrasted with others, who did not go beyond a descriptive focus of the plants physical characteristics. This teacher displayed an ability to guide students towards the 'why', which is important in higher scientific thinking as well as geospatial.

\section{Reflections and implications}

While the ubiquity of smartphones, web-based geospatial systems, web 2.0 technologies and familiarity with associated applications potentially engender increased uptake, mobile technology in education is still underdeveloped. The GeoSciTeach application indicates that smartphone technology when geared toward a specific task, target audience, and subject matter can be a powerful catalyst for educational change and knowledge acquisition. However, this project raises a number of barriers that contribute to effective uptake.

True innovation and embedding into practice requires considerable attention to the community of users, both as individual practitioners, and as part of teaching practice where curricular considerations are critical. While the application aimed to support two levels of learning for PSTs (developing geospatial awareness and knowledge, and integrating geospatial ideas into science), a key issue with respect to curriculum arose. Embedding technology into a curriculum that does not yet exist is opportune for the design of a new tool, but heightens the associated learning curve. While some geospatial notions are implicit in science (e.g. habitat distributions) explicit development of geospatial ideas is not apparent beyond geography. Comprehensive mapping of spatial thinking to science needs to be made more explicit. A preliminary table mapping these ideas has been developed (Farr et al., 2011) for PSTs, but further specification is needed if the teaching of geospatial skills in science is to be fostered. As geospatial integration in science is still an emerging curriculum, in contrast to in-service teachers, PSTs are able to adopt viewpoints on education without institutional interference, have more time to explore educational theory, and are learning the craft of teaching without regular classroom pressures.

Conversely PSTs were required to not only master the technology, but also develop their understanding of 'geospatial in science', in addition to learning how to become a science teacher. This highlights a disadvantage of working with PSTs, as their time was also limited for engaging longitudinally on this kind of project. While the iterative design workshops worked well, little input through blogging was received from PSTs, suggesting the 'between workshop' trials of new design features was limited. Furthermore, follow-up feedback beyond the end of their training was problematic. On the other hand a number of benefits were apparent. Working with PSTs enabled a design that suited different confidence levels with technology, and cultivated new 
perspectives for teaching practice activity at an early stage in their career development. PSTs not directly involved in the project showed little interest in the application, but those who were showed greater engagement with its use in Kew, and reaped rewards as their students focused more on geospatial relationships. Of the PSTs, only two were expert users of mobile applications, individuals with prior technological know-how. However, expert knowledge did not lessen the enthusiasm of other participants, as all continued to engage up to three months after teacher training was complete. This suggests the participatory design process is beneficial for fostering new developments in teaching, be they technical or curricular.

The application was comprehensive in offering broad opportunities for data capture, while aspects of the application e.g. easy access to stored files, loading of the map screen due to wifi reliance, need further work. Future work could also refine options for data capture by enabling capture of a silhouette of any object for comparative purposes; and consider flexible ways to use QR codes. While QR codes are becoming more common with a number of curators, their ease of production offers a useful way for teachers to customise their own learning artefacts in out-ofclassroom environments. Developing ways to productively bring these two together is important in fostering flexible use of QR codes. Effective development and refinement of GIS applications, in an area of the curriculum that currently does not exist, can only occur alongside iterative design, user feedback, professional development and curriculum development, requiring larger scale projects that also include practising teachers.

\section{Acknowledgements}

This work was funded by JISC: Geospatial Strand. We thank all pre-service teachers who took part in the project, and teachers and pupils from Ellen Wilkinson School.

\section{References}

Anand, S., Batty, M., Crooks, A., Hudson-Smith, A., Jackson, M., Milton, R., \&Morley J. (2010). Data mash-ups and the future of mapping JISC: Bristol.

Bonwell, C. \& Eison, J. (1991). Active Learning: Creating Excitement in the Classroom AEHE-ERIC Higher Education Report 1. Washington: Jossey-Bass

Demirci, A. (2009). How do Teachers Approach New Technologies: Geography Teachers' Attitudes towards Geographic Information Systems. European Journal of Educational Studies 1(1), 43-53.

Farr, W., Davies, P., Price, S., Roussos, G., Jewitt, C., \& Sinn, G. (2011). http://geosciteach.wordpress.com/2011/11/04/going-geospatial-in-science-a-framework-forteachers/ Retrieved April 2012

Hopson, M., Simms R. \& Knezek, G. (2002). Using a Technology enriched Environment to Improve Higher-order Thinking Skills. Journal of Research on Technology in Education. 34, 2, 109-119

Janelle, D. G. \& Goodchild, M.F. (2009). Locations across disciplines: Reflections on the CSISS Experience. In (eds) H. Scholten, R. van de Velde, N. van Manen, Geospatial Technology and the Role of Location in Science. Springer

Judge, S. (2011). How People Use Their Phones. Mobile Phone development: insights into developing for mobile http://mobilephonedevelopment.com/archives/1327 Retrieved December 2012

Kanjo, E., Benford, S., Paxton, M., Chamberlain, A, Stanton Fraser, D., Woodgate, D., Crellin, D. \& Woolard, A. (2007). MobGeoSen: Facilitating Personal GeoSensor Data Collection and Visualization using Mobile Phones. Personal and Ubiquitous Computing, Springer.

Kerski, J. (2008). Developing Spatial Thinking Skills in Education and Society. ArcWatch: Your eMagazine for GIS News, Views, and Insights. January.

Kirsch, D. (2010). Thinking with external representations. AI \& SOCIETY: Journal of Knowledge, Culture and Communication, 25(4), 441-454.

Martin, S., Stanton Fraser, D., Fraser, M., Woodgate, D. and Crellin, D. (2010). The impact of hand held mobile technologies upon children's motivation and learning. 9th World Conference on Mobile and Contextual Learning, October, Malta.

Niess, M. (2005). Preparing teachers to teach science and mathematics with technology: Developing a technology pedagogical content knowledge. Teaching and Teacher Education. 21 509-523

Rogers, Y. \& Price, S. (2008). The Role of Mobile Devices in Faciliating Collaborative Inquiry in Situ. Research and Practice in Technology Enhanced Learning. 3(3), 209-229. 
Sharples, M., Taylor, J. \& Vavoula, G. (2010). A Theory of Learning for the Mobile Age. In B. Bachmair (ed.) Medienbildung in neuen Kulturräumen. Stuttgart, Kohlhammer Verlag, pp. 87-99.

Simpson, D., Jackson, M., \& Aycock, J. (2005). John Dewey and Art of Teaching: Toward Reflective and Imaginative Practice. Sage, London.

Spinuzzi, C. (2005). The Methodology of Participatory Design. Technical Communication. 52, (2), May.

Vygotsky, L. (1986). Thought and language, revised edn. MIT Press, Cambridge

Xu, F., Guo, W., Xu, W., Wei, Y. \& Wang, R. (2009). Leaf Morphology Correlates with Water and Light Availability: What Consequences for Simple and Compound Leaves? Progress in Natural Science, 19 1789-1798

\section{Links}

Project web-site: http://geosciteach.wordpress.com/

Project blog: http://geosciteach.wordpress.com/blog/

Leaf Morphology: http://en.wikipedia.org/wiki/File:Leaf morphology.svg

GeoSciTeach toolkit for teachers:

http://geosciteach.wordpress.com/2011/11/11/science-goes-geospatial-with-geosciteach-ateacher-toolkit-for-integrating-geospatial-concepts-into-science-learning/

\begin{tabular}{|c|c|c|c|c|c|}
\hline $\begin{array}{l}\text { Geospatial } \\
\text { theory }\end{array}$ & Description & $\begin{array}{l}\text { Sub- } \\
\text { description }\end{array}$ & $\begin{array}{l}\text { Using } \\
\text { GeoSciTeach } \\
\text { app }\end{array}$ & $\begin{array}{l}\text { Geospatial } \\
\text { functionality (of } \\
\text { app) }\end{array}$ & Geospatial skill \\
\hline \multirow[t]{3}{*}{ Descriptive } & $\begin{array}{l}\text { Location: } \\
\text { Where } \\
\text { entity is }\end{array}$ & $\begin{array}{l}\text { Identificatio } \\
\mathrm{n} \text { of } \\
\text { absolute } \\
\text { place }\end{array}$ & $\begin{array}{l}\text { GoogleMap } \\
\text { e.g. Kew } \\
\text { (where you } \\
\text { are now) }\end{array}$ & $\begin{array}{l}\text { Representation of } \\
\text { point locations } \\
\text { within model. }\end{array}$ & $\begin{array}{l}\text { Understand \& } \\
\text { identify own location } \\
\text { Identify \& } \\
\text { understand location } \\
\text { of collected data }\end{array}$ \\
\hline & $\begin{array}{l}\text { Environmen } \\
\text { t measure }\end{array}$ & $\begin{array}{l}\text { e.g. soil, } \\
\text { humidity, } \\
\text { temperature }\end{array}$ & $\begin{array}{l}\text { Record } \\
\text { ambient data } \\
\text { \& record link } \\
\text { to location } \\
\text { (country) }\end{array}$ & $\begin{array}{l}\text { Associate meta-data } \\
\& \text { multi-media } \\
\text { resources with } \\
\text { specific points } \\
\text { /areas }\end{array}$ & $\begin{array}{l}\text { Identify \& label } \\
\text { capturing, } \\
\text { preserving, } \\
\text { conveying } \\
\text { appearances }\end{array}$ \\
\hline & Feature & $\begin{array}{l}\text { Shape, } \\
\text { colour, size, } \\
\text { texture etc }\end{array}$ & $\begin{array}{l}\text { Take a photo } \\
\text { \& Upload to } \\
\text { GoogleEarth }\end{array}$ & $\begin{array}{l}\text { Rendering } \\
\text { associated data with } \\
\text { specific location } \\
\text { into viewable image }\end{array}$ & \\
\hline $\begin{array}{l}\text { Analytic } \\
\text { Understand } \\
\text { structure of } \\
\text { objects \& } \\
\text { phenomena }\end{array}$ & $\begin{array}{l}\text { Comparison } \\
\text { relationship } \\
\text { s and } \\
\text { patterns }\end{array}$ & $\begin{array}{l}\text { Spatial, } \\
\text { feature \& } \\
\text { behaviour } \\
\text { relations }\end{array}$ & $\begin{array}{l}\text { Photo } \\
\text { tagging - } \\
\text { relationship } \\
\text { of one place } \\
\text { compared to } \\
\text { another }\end{array}$ & $\begin{array}{l}\text { Ability to render } \\
\text { model projections } \\
\text { from different } \\
\text { points of view }\end{array}$ & $\begin{array}{l}\text { Reasoning about } \\
\text { data } \\
\text { Calculate \& define } \\
\text { distance \& route } \\
\text { Seeing patterns in } \\
\quad \text { data }\end{array}$ \\
\hline
\end{tabular}




\begin{tabular}{|l|l|l|l|l|}
\hline $\begin{array}{l}\text { Inferential } \\
\text { Functional } \\
\& \\
\text { evolutionary } \\
\text { The 'why'? }\end{array}$ & $\begin{array}{l}\text { Integrating } \\
\text { complex } \\
\text { data } \\
\text { Calculate } \\
\text { relationshi } \\
\text { ps e.g. time } \\
\text { or distance }\end{array}$ & $\begin{array}{l}\text { Leaf } \\
\text { overlay/ } \\
\text { silhouette }\end{array}$ & $\begin{array}{l}\text { Ability to calculate } \\
\text { relationships } \\
\text { between areas, } \\
\text { features and points } \\
\text { e.g. containment } \\
\text { Ability to calculate } \\
\text { properties of } \\
\text { specific areas e.g. } \\
\text { convexity }\end{array}$ & $\begin{array}{l}\text { Understanding } \\
\text { structure of objects } \\
\text { Space in 2/ 3D } \\
\text { Giving answer to } \\
\text { evolution and } \\
\text { functions of objects }\end{array}$ \\
& & & $\begin{array}{l}\text { Cartographic } \\
\text { configuration } \\
\text { showing } \\
\text { relationships } \\
\text { between places }\end{array}$ \\
\hline
\end{tabular}

Table 1: Geospatial theory underpinning GeoSciTeach
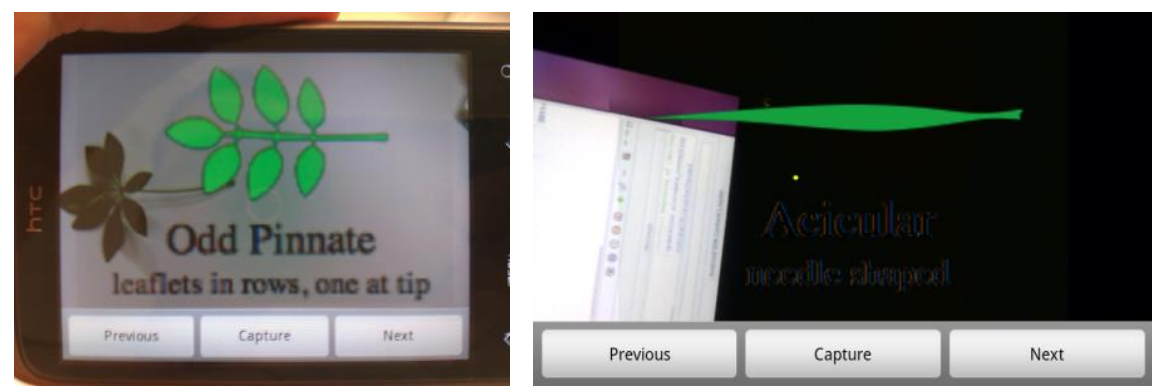

Figure 1: Leaf capture overlay

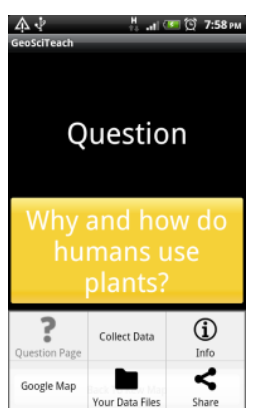

Figure 2: Question page with menu

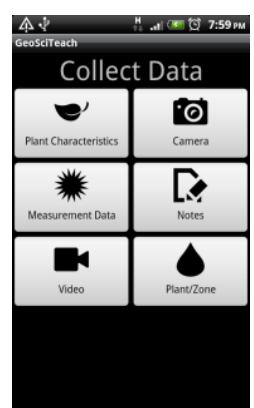

Figure 3: Collect data page

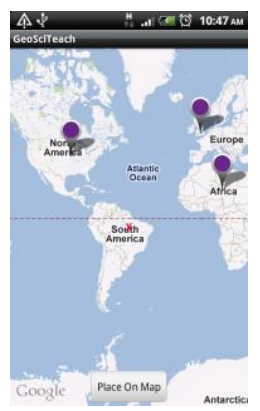

Figure 4: GoogleMaps with placepins 